\title{
Preservation of Human Kidneys for Transplantation: Preliminary Results with a Gambro Perfusion Machine
}

\author{
T. P. STEPHENSON, E. P. N. O'DONOGHUE, W. F. HENDRY, J. E. A. WICKHAM
}

British Medical fournal, 1973, 1, 379-381

\section{Summary}

Twenty-six human cadaveric kidneys have been preserved for up to 36 hours by continuous perfusion with $4.5 \%$ albumin solution on a Gambro machine. Of these, 20 kidneys were transplanted, and six were discarded owing to poor perfusion characteristics during storage. Immediate function was obtained with four kidneys, of which two had been preserved for over 30 hours.

Satisfactory renal function has been obtained with 17 kidneys, and three kidneys were lost owing to rejection or technical complications. It is our experience that human kidneys can be successfully preserved for up to 36 hours by this technique.

\section{Introduction}

Good HL-A matching in renal cadaveric transplantation significantly improves the transplant survival rate (Dausset and Hors, 1972; Oliver et al., 1972), but this can be achieved only by transporting kidneys from one centre to another, and this delay may lead to the transplantation of unfresh kidneys. As a result, it has been suggested that a policy of using poorly-matched living kidneys may be preferable to using well-matched dead ones (British Medical Fournal, 1972).

Kidneys may be preserved for up to 16 hours by initial perfusion and immersion in ice slush (Sells and Pena, 1970; Barnes et al., 1972). Simple storage techniques give consistently satisfactory results provided that the total ischaemia time does not exceed 10 hours (Hulme et al., 1972), and particularly good results have been reported (Milliez et al., 1972) with kidneys removed before death. However, with kidneys removed after death and distributed according to the results of tissue typing studies, immediate function becomes less likely once the cold ischaemia time exceeds 10 hours (Claes et al., 1971), and 16-20\% of such kidneys preserved by simple techniques may never function at all (Brunius et al., 1968; Festenstein et al., 1971). Improved techniques are clearly needed if the full benefit of tissue typing is to be realized, which should permit longer preservation, more frequent immediate function, and ready recognition of irreversibly damaged grafts so that they may be discarded before transplantation. Belzer and Kountz (1970) showed that these objectives could be achieved by continuous perfusion, but their machine is complex and the perfusate solution-cryoprecipitated plasma-is difficult to prepare.

The Gambro machine has been developed by Claes et al. (1970) as a simple and practical alternative to the Belzer apparatus, and the albumin solution used as perfusate is readily available. Preliminary studies showed that canine kidneys could be successfully preserved for up to 72 hours with immediate function (Claes and Blohme, 1971), and satisfactory results

Department of Urology, St. Bartholomew's Hospital, London EC1A $7 \mathrm{BE}$

T. P. STEPHENSON, F.R.C.S., Research Fellow

E. P. N. O'DONOGHUE, F.R.C.S., Senior Registrar

J. E. A. WICKHAM, M.S., F.R.C.S., Consultant Urologist

St. Peter's Hospital and the Institute of Urology, London WC28 8JE W. F. HENDRY, CH.M., F.R.C.S., Senior Lecturer

have subsequently been reported with 80 cadaveric kidneys preserved for up to 25 hours (Claes et al., 1972). After studying this technique at the transplantation unit in Gothenburg, we have introduced this preservation system in the London Transplant Group. Preliminary results are reported with 26 cadaveric kidneys.

\section{Materials and Methods}

The machine consists of a disposable perfusion circuit (fig. 1) housed in an insulated cabinet, which contains the controls, batteries, motors, and gas cylinder (fig. 2). Iced water is circulated through a heat exchanger under thermostatic control, and this maintains the temperature at about $5^{\circ} \mathrm{C}$. Perfusate is pumped at a constant rate through the heat exchanger and membrane oxygenator, which is gassed with a $66 \%$ nitrogen, $33 \%$ oxygen, $1 \%$ carbon-dioxide mixture. In a second circuit perfusate is pumped through a filter and bubble trap to the kidney. Flow is adjusted to give a perfusion pressure of $60 \mathrm{~mm}$ $\mathrm{Hg}$ systolic, and flow rate is measured by timing the speed of the roller pump. Temperature is checked by a small thermometer placed in the organ chamber beside the kidney.

The perfusate medium consists of human serum albumin $20 \%$ (Kabi) $200 \mathrm{ml}$, saline solution $(0.9 \mathrm{~g} / 100 \mathrm{ml}) 500 \mathrm{ml}$, glucose solution $(5.5 \mathrm{~g} / 100 \mathrm{ml}) 100 \mathrm{ml}$, soluble insulin 80 units, magnesium sulphate $10 \mathrm{mEq}$, potassium chloride $4 \mathrm{mEq}$, papaverine $\mathrm{HCl} 40 \mathrm{mg}$, benzylpenicillin 1 million units, hydrocortisone $100 \mathrm{mg}$, and sodium bicarbonate about $20 \mathrm{mEq}$ (to adjust $\mathrm{pH}$ to $7 \cdot 0-7 \cdot 2$ ).

Twenty-six consecutive human cadaveric kidneys passing through the London Transplant Group have been preserved with this machine. Donors were aged between 7 and 51 years.

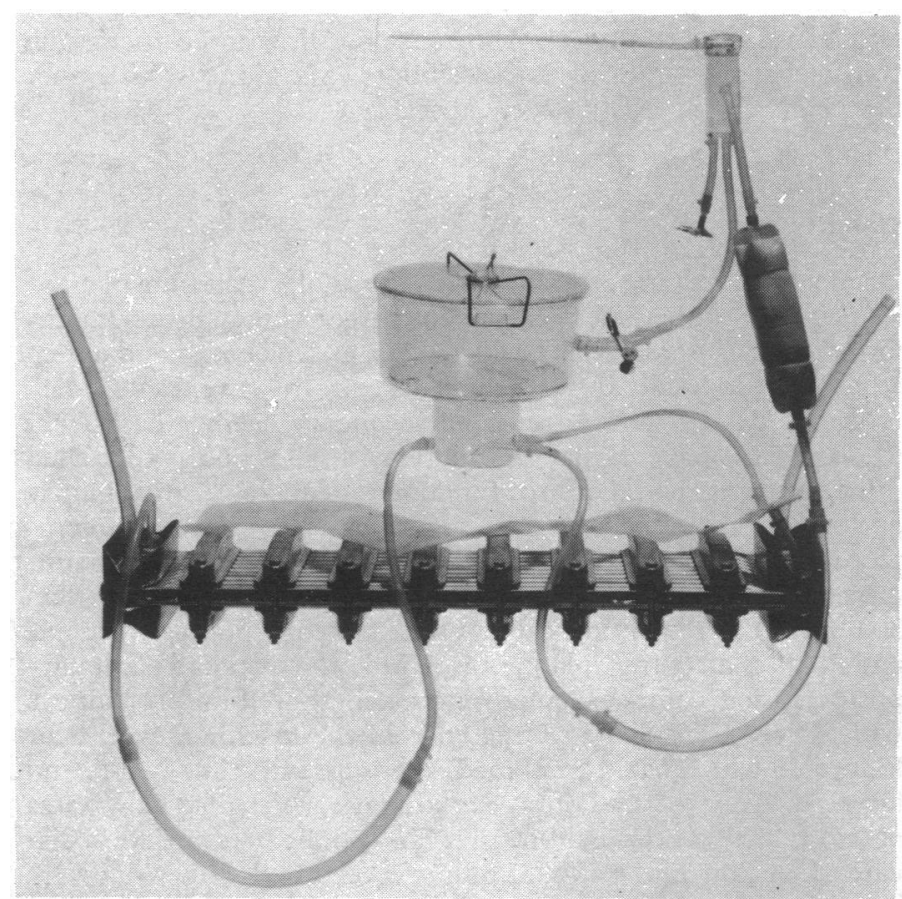

FIG. 1-The disposable perfusion circuit. 


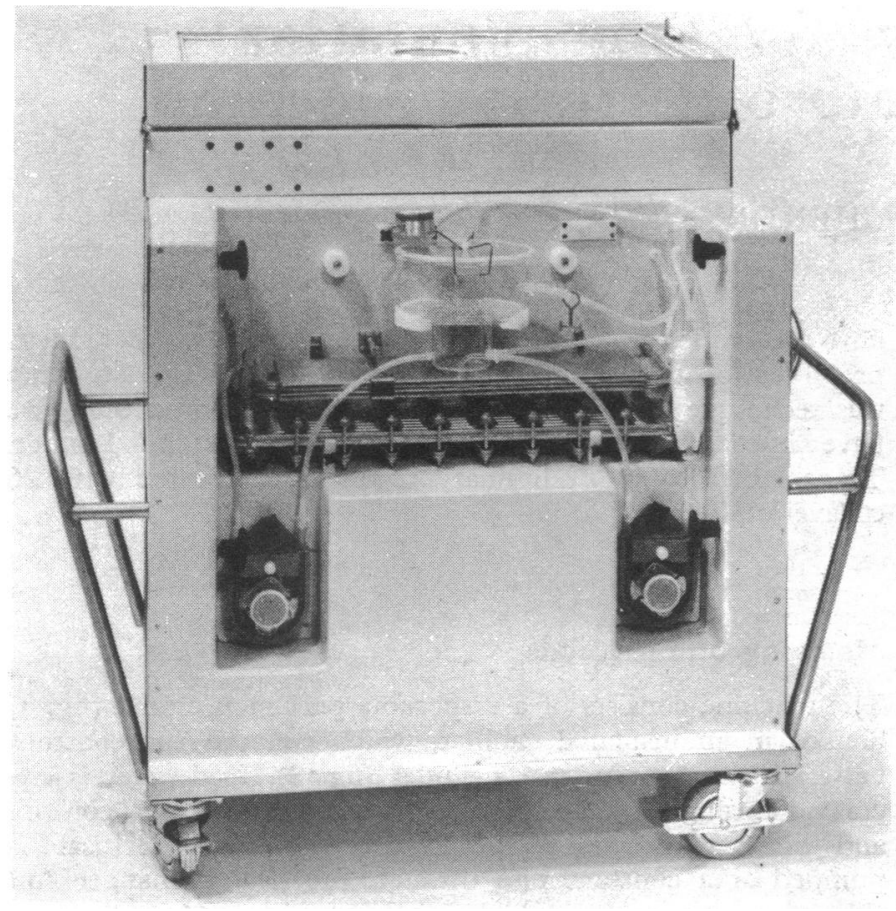

FIG. 2-The kidney perfusion machine (Gambro).

Initial warm ischaemia time varied between five and 60 minutes (mean 27 minutes). All kidneys flushed well on initial perfusion, using low molecular weight dextran solution, Perfudex, Gelin's solution (Gelin et al., 1967), or Collins's solution (Collins et al., 1969). All kidneys would have been regarded as acceptable for transplantation by criteria used before the introduction of this preservation system. Kidneys were preserved in ice-slush for 2 to 10 hours during transport to the machine (mean preperfusion cold ischaemia time five hours). They were then continuously perfused in the laboratory for $2 \frac{1}{2}$ to 27 hours (mean perfusion time 10 hours). On 14 occasions the machine was transported to the recipient hospital, and kidney perfusion was maintained until reimplantation was begun. One kidney was transferred to a second Gambro machine from Gothenburg at an airport, after an intermediate ischaemic interval of three hours (kidney No. 23). Five kidneys were removed from the machine and transported to the recipient in ice-slush, with postperfusion cold ischaemia times of 1 to 10 hours. Six kidneys with poor pe-fusion characteristics were discarded.

\section{Results}

The overall results are shown in the table. All transplanted kidneys have functioned, except for three: kidney 8 became infarcted owing to arterial occlusion by a detached fragment of atheroma; kidney 20 was removed on the twentieth postoperative day because of repeated secondary haemorrhage from the arterial anastomosis; and kidney $21-$ a poorly matched third transplant-failed to function adequately, and biopsy performed three weeks after transplantation showed microscopical evidence of rejection. Four kidneys have shown immediate function, of which two were preserved for more than 30 hours. The remaining kidneys started to function between five and 28 days after transplantation. Kidneys which had secondary postperfusion cold ischaemia functioned as well as any kidneys which were transplanted directly from the machine, except for kidney 14 which had a combined cold ischaemia time before and after perfusion of 14 hours. Six kidneys which had flow rates of less than $100 \mathrm{ml} / \mathrm{min}$ at $60 \mathrm{~mm} \mathrm{Hg}$ systolic pressure were discarded. A flow rate of $84 \mathrm{ml} / \mathrm{min}$ was recorded with kidney 13, which was removed from a child of 8 , and since this seemed adequate for such a small kidney, it was transplanted with satisfactory results.

The creatinine clearance of 12 kidneys had risen to over 40 $\mathrm{ml} / \mathrm{min}$ within six weeks (see table). Kidney 7 had undergone several rejection episodes and clearance was steady at 25-30 $\mathrm{ml} / \mathrm{min}$. Kidney 26 showed immediate function after preservation for $36 \frac{1}{2}$ hours, and clearance rose to. $38 \mathrm{ml} / \mathrm{min}$ by the tenth post-transplant day; however, this kidney has since been removed because of rejection. The patient who received kidney 17 died of aspiration pneumonia on the third postoperative day, at which time the kidney was functioning well. Kidneys 14 and 23 lowered the serum creatinine to 2.0 . and $2.1 \mathrm{mg} / 100 \mathrm{ml}$ at seven and five weeks respectively, but clearances are not available.

Bacterial culture of the perfusate medium was sterile in every case.

Results of Continuous Perfusion of Cadaveric Kidneys

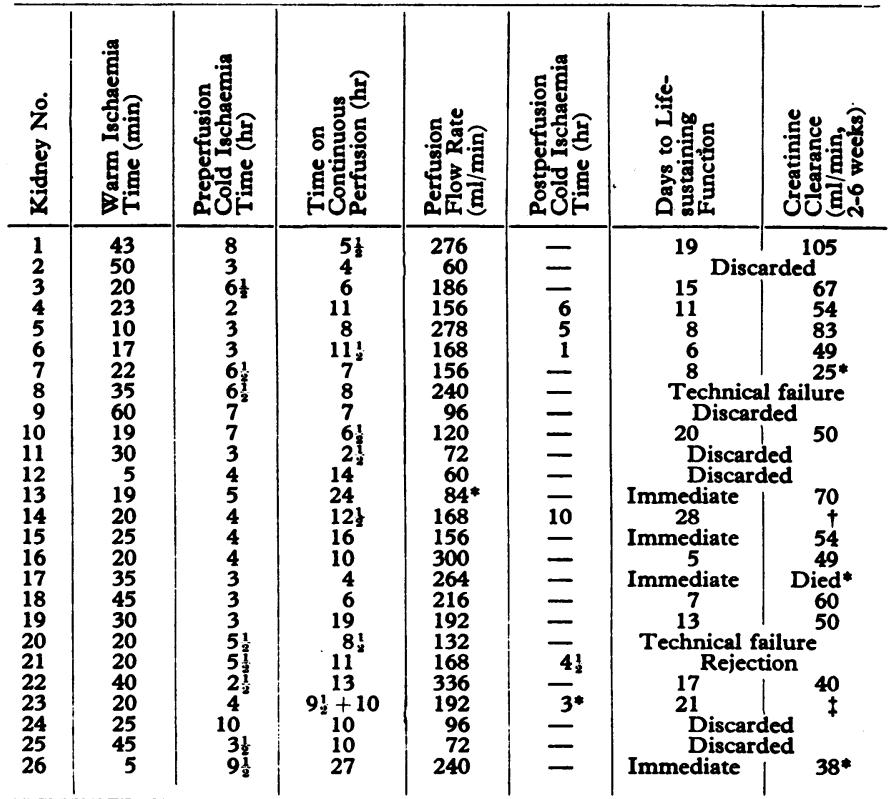

* See text.

† Serum creatinine $2.0 \mathrm{mg} / 100 \mathrm{ml}$ at seven weeks. No clearance available.

† Serum creatinine $2 \cdot 1 \mathrm{mg} / 100 \mathrm{ml}$ at five weeks. No clearance available.

\section{Discussion}

These observations confirm that this machine provides a satisfactory method of continuous perfusion of cadaveric kidneys in clinical transplantation, which allows sufficient time for tissue typing studies to be completed without undue haste. Kidneys can then be transported to well-matched, adequately prepared recipients, and transplantation may be performed as an elective procedure at a convenient time.

The apparatus has proved simple to operate and could be assembled and ready for use in 30-45 minutes. The albumin perfusate was particularly convenient compared to cryoprecipitated plasma. Cooperman et al. (1971), however, reported poor results with a solution containing powdered albumin (fraction V), and analysis has shown appreciable differences in the fatty acid content of powdered albumin and the Kabi albumin used in the Gambro machine (Horsburgh, 1973), which may be important in obtaining satisfactory results.

Six kidneys were discarded because of poor perfusion characteristics during preservation. In a similar co-operative programme in Cleveland, Kiser et al. (1971) reported that only 22 of 38 cadaveric kidneys were transplanted after assessment of viability during continuous perfusion, and 17 of these kidneys subsequently functioned well. Belzer et al. (1970) have shown that renal vasoconstriction occurs primarily during the agonal period and persists during isolated perfusion and after trans- 
plantation. Since all of the kidneys discarded in this study perfused well with the initial perfusate solution, continuous perfusion probably provides a more satisfactory method of screening cadaveric kidneys before transplantation.

Continuous perfusion of human cadaveric kidneys has been reported from San Francisco (Belzer and Kountz, 1970), Los Angeles (Moore et al., 1971), Richmond (Sterling et al., 1971), New York (McCabe and Fitzpatrick, 1972), Cleveland (Kiser et al., 1971), and Gothenburg (Claes et al., 1972). In some centres the perfusion machine is mobile, being taken to both donor and recipient hospitals with the kidney; in others, kidneys are brought to a central perfusion laboratory in ice. Scott et al. (1971) have shown that cold ischaemia is better tolerated in dogs before, rather than after, a period of continuous perfusion, and hence concluded that kidneys could be removed at local hospitals and transported to the preservation laboratory in ice, but they did not recommend transporting stored kidneys in ice after continuous perfusion. In Scandinavia, G. Claes (personal communication, 1972) has preferred to take the perfusion machine to the recipient if possible. However, Kiser et al. (1971) concluded that with human kidneys postperfusion cold ischaemia of up to $3 \frac{3}{4}$ hours did not affect the function of the kidney adversely. The results of this study appear to confirm this conclusion, although it seems that if the combined cold ischaemia times before and after perfusion exceed 10 hours onset of renal function is likely to be delayed.

The introduction of this preservation system has extended greatly the period during which cadaveric kidneys may be stored. Immediate function has been obtained after preservation for up to 36 hours, and kidneys have been discarded which previously would have been transplanted probably with poor subsequent function. It is expected that the results of cadaveric kidney transplantation should be significantly improved by routine preservation by continuous perfusion, and the assessment of viability before transplantation to well-matched recipients.

We wish to thank the staff of the transplantation units of the following hospitals for kindly providing information on the function of the kidneys: Queen Elizabeth Hospital, Birmingham; Jervis Street Hospital, Dublin; Western General Hospital, Edinburgh; Sahl- grenska Sjukhuset, Gothenburg; Academisch Ziekenhuis, Leiden; Charing Cross, Guy's, Hammersmith, The London, Royal Free, and the Westminster Hospitals, London; and the Royal Victoria Infirmary, Newcastle.

We also wish to thank the transplant immunology unit at the London Hospital Medical College, and the National Organ Matching Service, Bristol, for their help and co-operation.

Financial support was provided by the Boards of Governors of St. Bartholomew's Hospital and St. Peter's Hospitals, and by the St. Peter's Research Trust and the Institute of Urology.

\section{References}

Barnes, A. D., Dawson-Edwards, P., Powis, S. J. A., and Thomas, D. R. (1972). Lancet, 1, 199.

Belzer, F. O., and Kountz, S. L. (1970). Annals of Surgery, 172, 394

Belzer, F. O., Reed, T. W., Pryor, J. P., Kountz, S. L., and Dunphy, J. E. (1970). Surgery, Gynecology and Obstetrics, 130, 467.

British Medical fournal, 1972, 3, 251.

Brunius, U., Bergentz, S. E., Ekman, H., Gelin, L. E., and Westberg, G. (1968). Scandinavian fournal of Urology and Nephrology, 2, 15.

Claes, G., Aurell, M., and Brunius, U. (1970). Nordisk Medicin, 84, 923.

Claes, G., and Blohme, I. (1971). Nordisk Medicin, 86, 881.

Claes, G., Blohme, I., and Gelin, L. E. (1971). Proceedings of the European Dialysis and Transplant Association, 8, 307.

Claes, G., Aurell, M., and Blohme, I. (1972). Proceedings of the European Dialysis and Transplant Association. 9,484

Collins, G. M., Bravo-Sugarman, M., and Terasaki, P. I. (1969). Lancet, 2, 1219.

Cooperman, A. M., Woods, J. E., Holley, K. E., and McIlrath, D. C. (1971). Mayo Clinic Proceedings, 46, 193.

Dausset, J., and Hors, J. (1972). Nature New Biology, 238, 150.

Festenstein, H. et al. (1971). Lancet, 2, 225.

Gelin, L. E. et al. (1967). Fournal of Cardiovascular Surgery (special issue) 8th Congress of the International Cardiovascular Society, Vienna, September 1967, p. 78.

Horsburgh, T. (1973). Nature. In press.

Hulme, B., Snell, M. E., Kenyon, J. R., Owen, K., and Peart, W. S. (1972). British Medical fournal, 4, 139.

Kiser, W. S., Magnusson, M. O., McLaughlin, T. C., Hewitt, C. B., and Straffon, R. A. (1971). Fournal of Urology, 105, 779.

McCabe, R. E., and Fitzpatrick, H. F. (1972). Fournal of the American Medical Association, 219, 1056.

Milliez, P. et al. (1972). Lancet, 2, 887.

Moore, T. C., Berne, T. V., Martin, D. C., and English, T. S. (1971). Trans-

plantation, 12, 526.
Oliver, R. T. D., Sachs, J. A., and Festenstein, H. Pegrum G. D., and Moorhead, J. F., (1972). Lancet, 2, 1381 .

Scott, D. F., Stephens, F. O., Keaveny, T. V., Kountz, S. L., and Belzer, F. O. (1971). Transplantation, 11, 90

Sells, R. A., and Pena, J. R. (1970). Lancet, 2, 539.

Sterling, W. A., Pierce, J. C., Hutcher, N. E., Lee, H. M., and Hume, D. M. (1971). Surgical Forum, 22, 229.

\title{
Assessment of Acid-base Disturbances Employing a Desk-top Computer
}

\author{
A. W. GROGONO
}

British Medical fournal, 1973, 1, 381-386

\section{Summary}

Patients in an intensive care unit have had their acid-base status satisfactorily assessed for some months using a desktop computer. Any department able to juxtapose an Astrup apparatus and a programmable calculator will find the method convenient to use.

Royal Free Hospital, London NW3 2X]

A. W. GROGONO, F.F.A. R.C.s., Consultant Anaesthetist

\section{Introduction}

Acid-base disturbances are commonly assessed using the Astrup interpolation technique (Astrup, 1956; Siggaard Andersen et al., 1960; Siggaard Andersen and Engel, 1960; Mellemgaard and Astrup, 1960; Siggaard Andersen, 1962). Three $\mathrm{pH}$ readings are required for a complete determination of the patient's acid-base state; the pH of the original sample is measured as well as the $\mathrm{pH}$ of the blood when tonometered with two different mixtures of carbon dioxide and oxygen. The buffer line thus established is plotted on a nomogram from which may be read the patient's $\mathrm{PCO}_{2}$, standard bicarbonate, base excess, and buffer base. The technique has several advantages. Only a single electrode needs to be maintained, calibrated, and understood; use of the technique 